\title{
PENGARUH METODE LATIHAN TUTORIAL TEMAN SEBAYA DAN VIDEO TUTORIAL TERHADAP HASIL BELAJAR LAY UP SHOOT
}

\author{
Achmad Rizal Lukman ${ }^{1}$, Ardhian Tomy Kurniawan ${ }^{2}$ \\ Email : $\underline{\text { A810170002@ Student.ums.ac.id }}{ }^{1}, \underline{\text { Atk317@ } \text { ums.ac.id }^{2}}$ \\ ${ }^{\mathbf{1 , 2}}$ Program Studi Pendidikan Olahraga Fakultas Keguruan Ilmu Pendidikan Universitas \\ Muhammadiyah Surakarta
}

\begin{abstract}
Abstrak
Tujuan dari penelitian ini adalah untuk mengetahui pengaruh metode latihan tutorial teman sebaya dan vidio tutorial terhadap hasil latihan Lay Up Shoot. Dengan jumlah populasi yang diteliti adalah seluruh siswa Smp Islam Nurul Huda yang berjumlah 47 siswa. Dimana sempel di bagi menjadi 2 kelompok belajar. Kelompok pertama mendapatkan perlakuan atau pembelajaran dengan metode pembelajaran tutorial teman sebaya dan kelompok ke 2 mendapat perlakuan atau pembelajaran dengan metode vidio pembelajaran. Teknik pengumpulan data menggunakan tes lay up shoot dimana setiap siswa akan melakukan lemparan Lay Up Shoot sebanyak 10 kali dengan ketentuan semakin banyak yang masuk maka nila akan semakin baik. Tidak terdapat perbedaan yang pengaruh tutor sebaya terhadap hasil pembelajaran lay up shoot bola basket pada siswa SMP Islam Nurul Huda ditunjukkan nilai sig.(2-tailed) dari kelompok eksperimen yaitu 0,778. Tidak terdapat perbedaan yang signifikan pengaruh video tutorial terhadap hasil pembelajaran lay up shoot bola basket pada siswa SMP Islam Nurul Huda ditunjukkan oleh nilai sig.(2-tailed) dari kelompok eksperimen yaitu 0,170 . Tidak ada perbedaan tutorial teman sebaya dan vidio tutorial berpengaruh secara bersama terhadap pembelajaran bola basket. ditunjukkan nilai signifikansi $>0,005$. Dapat meningkatkan ketertarikan serta keantusiasan siswa Smp Islam Nurul Huda dalam mengikuti pembelajaran bola basket dengan metode tutorial teman sebaya dan vidio tutorial. Sebagai informasi tentang hambatan dan kendala yang dialami oleh siswa Islam Nurul Huda saat pembelajaran bola basket dengan metode tutorial teman sebaya dan video tutorial.
\end{abstract}

Kata Kunci: tutorial teman sebaya; vidio tutorial; lay up shoot.

\begin{abstract}
The purpose of this study was to determine the effect of peer tutorial training methods and video tutorials on the results of the Lay Up Shoot exercise. With the total population studied were all students of SMP Islam Nurul Huda, amount ot 47 students. Where the sample is divided into 2 study groups. The first group received treatment or learning with the peer tutorial learning method and the second group received treatment or learning with the video learning method. The data collection technique uses of lay up shoot test where each student will throw a Lay Up Shoot 10 times with the provision that the more people enter, the better the score will be collect. There is no difference that the influence of peer tutors on the learning outcomes of basketball lay-up shoots for students of SMP Islam Nurul Huda is shown by the sig. (2-tailed) value of the experimental group, which is 0.778 . There is no significant difference in the effect of video tutorials on the learning outcomes of lay up shoot basketball for students of SMP Islam Nurul Huda indicated by the value of sig.(2-tailed) from the experimental group, which is 0.170 . There is no difference in peer tutorials and video tutorials having a joint effect on basketball learning. indicated a significance value >0.005. The benefits of this research are as a Can increase the interest and enthusiasm of Nurul Huda Islamic Junior High School students in participating in basketball lessons with peer tutorial methods and video tutorials.
\end{abstract}


For information about the obstacles and obstacles experienced by Islamic students Nurul Huda when learning basketball with the peer tutorial method and video tutorials.

Keywords: peer tutorial; video tutorial; lay up shoot.

\section{A. Pendahuluan}

Olahraga merupakan kegiatan yang dapat meningkatkan kondisi fisik dan mental seseorang. Dalam rangka meningkatkan sumberdaya manusia olahraga tidak hanya dilakukan sebagai sarana untuk meningkatak kesehatan jasmani dan rohani saja, tetapi lebih untuk mendapatkan prestasai yang optimal dalam bidang olahraga guna mengangkat citra bangsa olahraga, karena ddengan prestasi yang baik dalam bidang olahraga dapat meningkatkan citra bangsa indonesia di kancah internasional. Dalam upaya untuk meningkatkan presatasai perlu adanya bimbingan sejak dini yang mengarahkan minat dan bakat calon atlet ke cabang yang tepat dengan demikian, minat dan bakat calon atlet dapat diasah dengan lebih baik serta memperoleh prestasi yang maksimal. Olahraga bola basket pertama diperkenalkan di amerika serikat sebagai permnainan untuk hiburan pada tahun 1891 oleh sekolah pelatihan fisik diamerika serikat.pada awalnya permainan ini hanyamemiliki sedikit peraturan dan ketentuan untuk memainkannya. Tidak butuh lama permainan bola basket dapat populer dan dimainkan oleh masyarakat dunia. Bola basket merupakan permainan bola besar yang dimainkan oleh 2 regu yang beranggotakan masingmasing 5 orang, permainan ini bertujuan memasukan bola kedalam kerangjang dan memperoleh poin sebanyak-banyaknya.

Bola basket adalah cabang olahraga permainan bola besar yang sangat menarik minat untuk ditonton dengan karakteristik tertentu. Usaha memasukkan bola ke dalam keranjang lawan dan mencegah regu lawan untuk memasukkan bola ke dalam keranjang adalah orientasi dan setiap tindakan di dalam permainan bola basket. Permainan bola basket memiliki nilai-nilai tertentu yang sifatnya universal. Metode pembelajaran sangat berpengaruh dalam tingkat pemahaman pembelajaran siswa SMP Islam Nurul Huda. Dalam pemeilihan metode harus yang menyenangkan dan tidak membuat bosan sehingga proses pembelajaran penjas akan berjalan efisien dan tingkat pemahaman siswa meningkat, dalam proses pembelajaran penjas menggunakan metode demonstrasi yaitu guru mempraktikan cara lay up yang benar kepada siswa. Salah satu metode yang mungkin dapat diterapkan dalam pembelajaran dari permasalahan yang ditemukan yaitu menggunakan metode tutorial teman sebaya dan metode teman sebaya. Dengan tutorial teman sebaya siswa berperan sebagai tutor unttuk membantu siswa laiannya dalam memahami materi sehingga kecanggungan dan kerenggangan selama proses pembelajaran dapat dihilangkan sehingga daya serap siswa meningkat. Vidio pembelajaran adalah metode yang menggunakan media sebagai alat dalam tranfer ilmupengetahuan dimana dalam metode ini menggunakan vidio yang diambil dari youtube untuk membantu menerangkan materi yang diajarkan. Dengan metode pembelajaran audio dan visual yang menarik diharapkan daya serap siswa meningkat. Tujuan dari penelitian ini adalah menemukan metode yang efektif dalam pembelajaran Lay Up Shoot bola basket antara metode tutorial teman sebaya dan vidio tutorial 


\section{B. Metode}

Dalam penelitian ini menggunakan pendekatan kuantitatif aktivitas peneliti digunakan untuk memperoleh data dan kesimpulan sebagai pondasi awal dalam proses analisis yang akan dilakukan nantinya. Waktu penelitian dilakukan pada bulan juli 2021agustus 2021 dengan memalui beberapa tahap dalam penelitian yaitu diawali dengan melakukan pre-test sebagai acuan dalm pengelompokan metode pembelajaran vidio tutorial dan teman sebaya, yang kemudian dilakukan post-test untuk mendapat data yang akurat. Dalam penelitian menggunakan alat bantu berupa instrumen penelitian untuk mempermudah memper oleh data. Penelitian dilakukan di Smp Islam Nurul Huda. Metode kuantitatif adalah metode yang berpegang dalam usaha untuk menguji teori yang telah ada. Dimana didalamnya berisi variable yang bisa dinilai menggunakan angka yang dapat dianalisis dengan statistikyang kemudian akan menemukan sebuah kesimpulan benar tidaknya suatu teori. Teknik pengumpulan data dalam penelitian ini menggunakan ujian praktik tes lay up shoot yang dilakukan dalam 2 tahap yaitu pre-test dan post-test. Dalam melakukan tes lay up shoot setiap peserta mendapat kesempatan 10 kali melakukan lemparan dengan ketentuan semakin banyak bola yang masuk maka nilai akan semakin baik.

\section{Hasil dan Pembahasan}

Data mentah penelitian berupa data empiris yang diperoleh melalui tes dan pengukuran variabel Lay up Tutorial Teman Sebaya dan variabel Lay up shoot Video Tutorial, sementara Pelaksanaan dalam mengumpulkan data pada test dribble dilakukan dengan cara setiap anak melakukan lemparan lay up shoot sebanyak 10 kali. Selanjutnya dianalisis dengan menggunakan teknik statistik deskriptif dan statistik inferensial. Analisis data deskriptif dimaksudkan untuk mendapatkan gambaran umum mengenai data dalam penelitian, kemudian dilanjutkan dengan pengujian persyaratan analisis yaitu uji normalitas data. Sedangkan analisis data secara inferensial dimaksudkan untuk mendapatkan hasil pengujian hipotesis yang diajukan dalam penelitian ini.

Tabel 1. Hasil Pretest dan Post test variabel Lay up Shoot Tutorial Teman Sebaya

\begin{tabular}{lll} 
Statistik & Pretest & Post Test \\
\hline $\mathrm{N}$ & 46 & 46 \\
Mean & 4,06 & 7 \\
Nilai Maksimum & 7 & 9 \\
Nilai Minimum & 2 & 5 \\
Jumlah Nilai & 187 & 322 \\
\hline
\end{tabular}

Berdasarkan data diatas diketahui julah sampel kelompok pretest dan adalah 46 siswa, dengan nilai maksimum 7 dan minimum 2, jumlah nilai 187 dan rata-rata 4,06. Sedangkan post-test lay up shoot dengan jumlah peserta 46 siswan memiliki nilai maksimum 9, nilai minimum 5, jumlah nilai 322 dan rata-rata 7 . Dari kedua kelompok tersebut peneliti menentukan kelompok pretest sebagai kelompok eksperimen dan post-test sebagai kelompok kontrol. Setelah kelompok eksperimen dilakukan kontrol kemudian dilakukan post-test secara keseluruhan. 


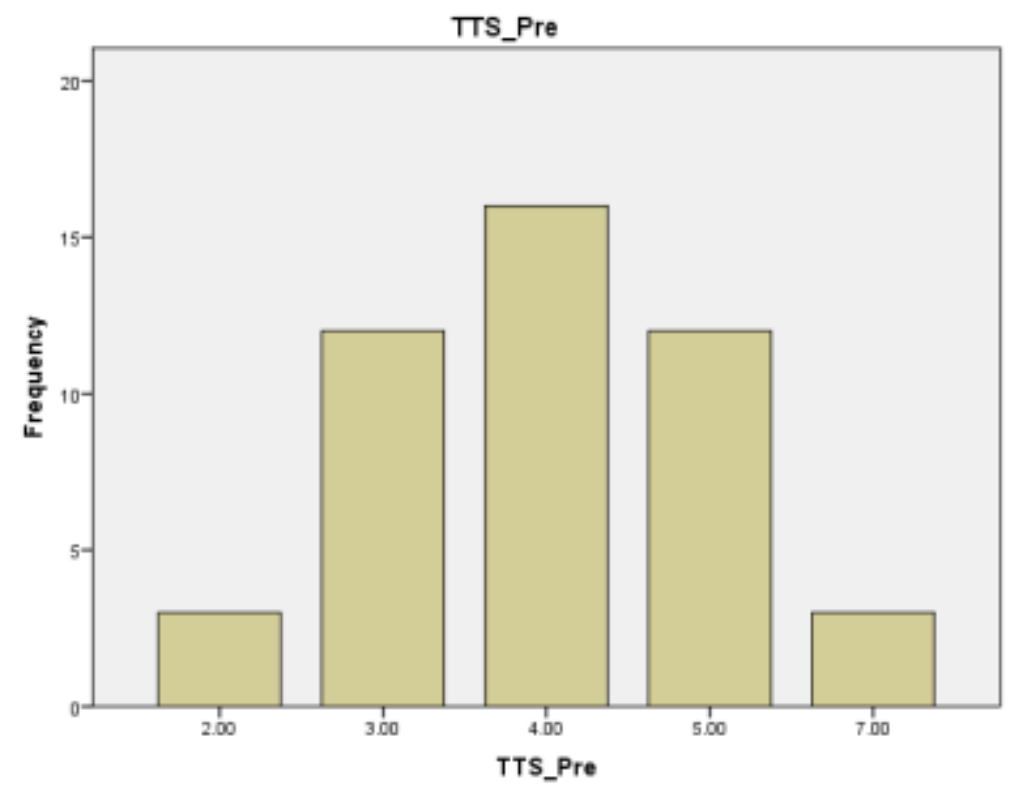

Grapik 1. Histogram Pretest variabel Lay up Shoot Tutorial Teman Sebaya

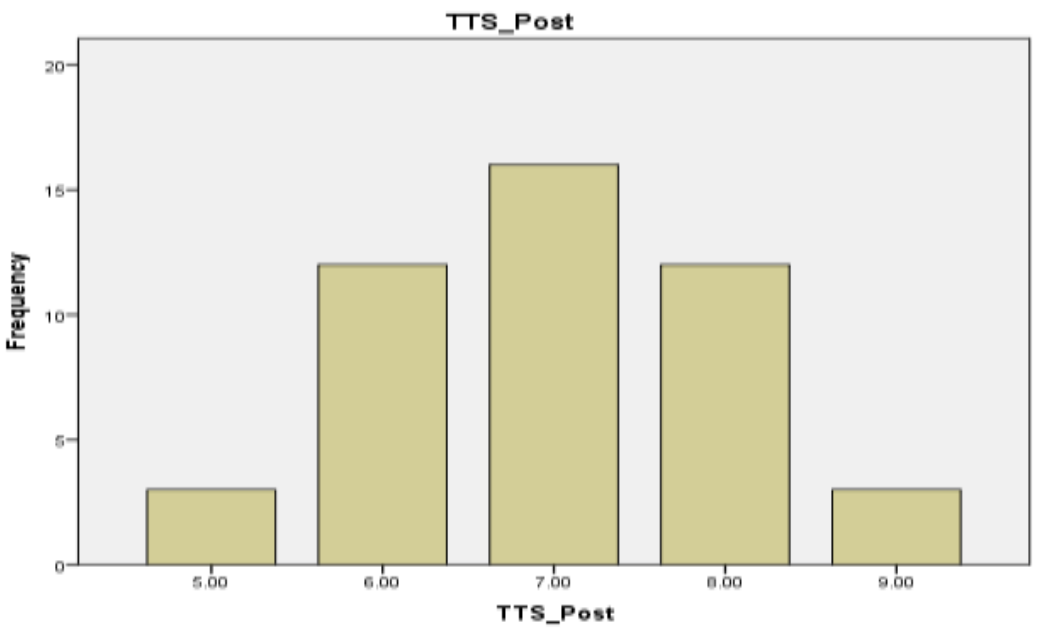

Grapik 2. Histogram variabel Post Test Lay up Shoot Tutorial Teman Sebaya

Tabel 2. Hasil Pretest dan Post test variabel Lay up Shoot Video Tutorial

\begin{tabular}{lll} 
Statistik & Pretest & Post Test \\
\hline $\mathrm{N}$ & 46 & 46 \\
Mean & 4,04 & 5,58 \\
Nilai Maksimum & 6 & 8 \\
Nilai Minimum & 2 & 4 \\
Jumlah Nilai & 186 & 257 \\
\hline
\end{tabular}

Berdasarkan data hasil pretest dan Posttest tersebut dapat diketahui bahwa untuk kelompok pretest dengan jumlah sampel 46 memiliki nilai maksimum 6, nilai minimum 2, jumlah nilai 186 dan nilai rata-rata 4,04, sedangkan untuk kelompok Post test dengan jumlah sampel 46 memiliki nilai maksimum 8, nilai minimum 4, jumlah nilai 257. Untuk kelompok Post test Peneliti mengelompokkan kelompok Post sebagai kelompok Eksperimen dan kelompok Pre test sebagai kelompok Kontrol. Sehingga dapat disimpulkan bahwa kelompok 
ekperimen mengalami peningkatan jumlah nilai dari 186 menjadi 257 dan rata-rata 4,04 menjadi 5,58.

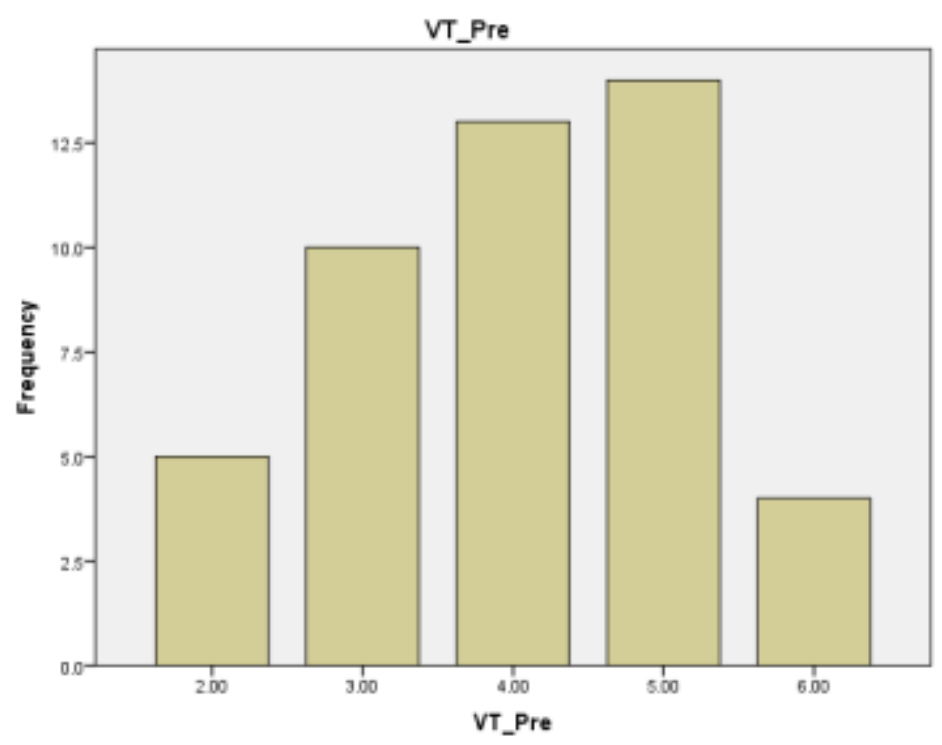

Grapik 3. Histogram Pre Test variabel Lay up Shoot Video Tutorial

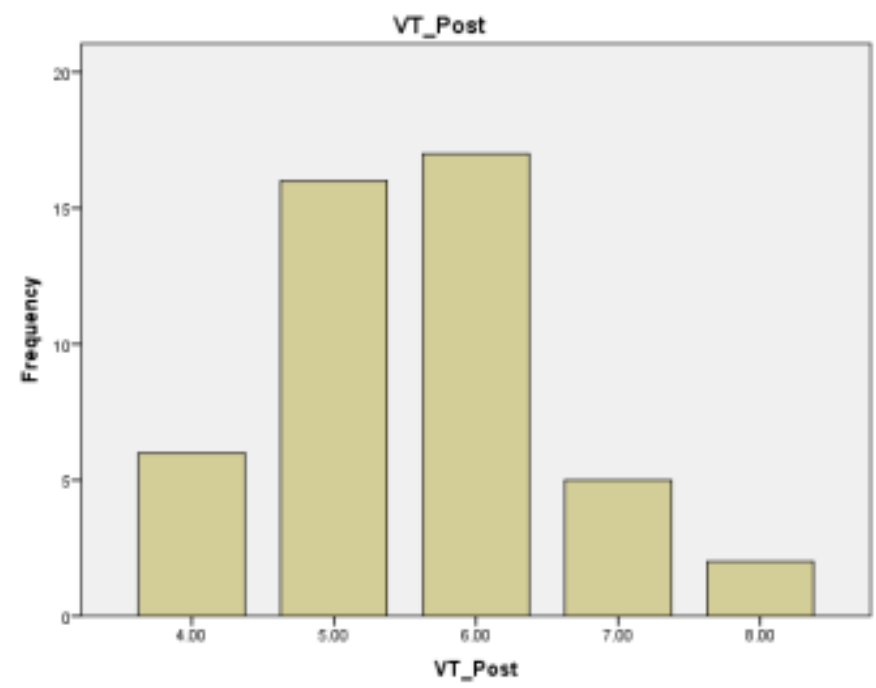

Grapik 4. Histogram Posttest variabel Lay up Shoot Video Tutorial

Tabel 3. Rangkuman hasil analisis deskripstif data Hasil Pretest dan Posttest

\begin{tabular}{|c|c|c|c|c|c|}
\hline \multicolumn{6}{|c|}{ Statistics } \\
\hline \multirow[t]{2}{*}{$\mathrm{N}$} & Valid & 46 & 46 & 46 & 46 \\
\hline & Missing & 0 & 0 & 0 & 0 \\
\hline \multicolumn{2}{|c|}{ Mean } & 4.0652 & 7.0000 & 4.0435 & 5.5870 \\
\hline \multicolumn{2}{|c|}{ Std. Deviation } & 1.18138 & 1.03280 & 1.15386 & 1.00169 \\
\hline \multicolumn{2}{|c|}{ Variance } & 1.396 & 1.067 & 1.331 & 1.003 \\
\hline \multicolumn{2}{|c|}{ Range } & 5.00 & 4.00 & 4.00 & 4.00 \\
\hline \multicolumn{2}{|c|}{ Minimum } & 2.00 & 5.00 & 2.00 & 4.00 \\
\hline \multicolumn{2}{|c|}{ Maximum } & 7.00 & 9.00 & 6.00 & 8.00 \\
\hline
\end{tabular}


Berdasarkan data statistik diatas dapat disimpulkan bahwa pada pretest lay up shoot Tutor sebaya sampel Pretest berjumlah 46 standar deviasi 1,18, dan nilai varian sebesar 1,9. dan Posttest dengan standar deviasi sebesar 1,03 atau dapat dikatakan semakin mengecil sehingga terdapat perbaikan hasil tutor sebaya dalam melaksanakan perannya. Pada lay up shoot video tutorial untuk sampel pretest berjumlah 46 dengan nilai standar deviasi sebesar 1.15 dan nilai varian data sebesar 1,33. Sementara pada postest memiliki standar deviasi sebesar 1.00 dan nilai varian sebesar 1,00. Hasil tersebut menunjukkan peran video tutorial meningkat dalam memberikan informasi kepada siswa. Peningkatan hasil pada latihan cukup dapat dilihat akan tetapi tidak terlalu signifikan.

Tabel 4. Tabel Normalitas Data

\begin{tabular}{crrrr}
$\begin{array}{c}\text { Uji } \\
\text { Normalitas }\end{array}$ & TTS_Pre & TTS_Post & VT_Pre & VT_Post \\
$\begin{array}{c}\text { Kolmogrov } \\
\text { Smirnov }\end{array}$ & & & & \\
\hline $\begin{array}{c}\text { Asymp.Sig } \\
\text { (2-tailed) }\end{array}$ & .059 & .124 & .078 & .052 \\
& & & & \\
\end{tabular}

Berdasarkan data statistik diatas dapat diketahui bahwa nilai signifikansi dari masingmasing variable yaitu sebesar 0,$059 ; 0,124 ; 0,078$; dan 0,052 . Nilai tersebut lebih besar dari $\alpha$ $=0,05$. Sehingga dapat disimpulkan bahwa data hasil dari data lay up shoot Tutor Teman sebaya, dan lay up shoot Video Tutorial tes Dribbel pada bola basket berdistribusi normal.

Tabel 5. Tabel Homogenitas Kelompok Pretest dan Posttest Lay up Shoot Tutorial Teman Sebaya

N
Nilai Signifikan Levene Statistik

\begin{tabular}{cc} 
Pretest & Posttest \\
\hline 46 & 46 \\
0,781 & 0,533
\end{tabular}

Tabel 6. Tabel Homogenitas Pretest dan Posttest Lay up Shoot Video Tutorial

\begin{tabular}{ccc} 
& Pretest & Posttest \\
\cline { 2 - 3 } N & 46 & 46 \\
Nilai Signifikan Levene Statistik & 0,698 & 0,063
\end{tabular}

Berdasarkan data statistik diatas dapat diketahui bahwa nilai signifikansi pada Pretest dan Posttest variable Tutorial Teman Sebaya, Video Tutorial dan Dribbel. Nilai tersebut lebih besar dari $\alpha=0,05$. Sehingga dapat disimpulkan bahwa varian kelompok pretest dan postest pada setiap variable dalam penelitian ini adalah sama atau homogen. 
Tabel 7. Pengujian Hipotesis Video Tutorial terhadap hasil pembelajaran lay up shoot bola basket

Paired Samples Test (Nilai t hitung)
Sig (2-tailed)

Kesimpulan

\section{Posttest Video}

Tutorial
1,396
Tidak ada perbedaan

signifikan

Berdasarkan data statistik diatas dapat diketahui bahwa nilai sig.(2-tailed) dari kelompok eksperimen yaitu 0,170 artinya tidak terdapat perbedaan yang signifikan antara Pretest dan Posttest, pengaruh video tutorial terhadap hasil pembelajaran lay up shoot bola basket pada siswa SMP Islam Nurul Huda, sehingga hipotesis penelitian ini ditolak. Hasil tersebut menunjukkan bahwa tidak ada perbedaan hasil pembelajaran Video Tutorial terhadap hasil pembelajaran lay up shoot bola basket siswa SMP Islam Nurul Huda

\section{Pembahasan}

Sesuai hasil penelitian yang telah dilakukan telah dijelaskan di atas lay up membutuhkan latihan dengan gerakan melompat setinggi- tingginya. Melompat setinggi tingginya untuk bisa memasukkan bola ke dalam ring memerlukan kondisi fisik kelentukan, kekuatan dan power otot tungkai yang maksimal. Dalam pertandinag bola basket untuk pemula untuk mencetak anggka lebih dominan mengguanakan teknik lay up dibandingkan teknik lainnya seperti shooting karena lay up memiliki kesempatan yang lebih besar untuk memasukan bola. Lay up sendiri dilakukan dengan cara lemparan sedekatdekatnya dengan ring sehingga presentasi untuk masuknya tinggi. Hasil penelitian ini membuktikan bahwa latihan lay up shoot belum dapat ditingkatkan pemain. Hal ini menjelaskan tentang pentingnya menjalankan latihan secara terus-menerus yang berkesinambungan sehingga seorang akan mengalami peningkatan dari segi fisik maupun teknik. Hal ini sejalan dengan prinsip latihan spesialisasi dimana sebuah latihan yang dilakukan secara kompleks yang didasari untuk meningkatkan keseluruhan fisik yang kemudian latihan tersebut difokuskan pada cabang olahraga tertentu. Hasil penelitian ini juga membuktikan bahwa program latihan yang perlu di susun secara terencana, dilakukan secara berulang-ulang dengan program latihan yang benar dan peningkatan beban latihan yang sesuai dapat meningkatkan performa seorang atlet. Khusunya dalam aspek kondisi fisik pemain dimana dalam penelitian ini keadaan fisik pemain khususnya pada bagian kekuatan daya ledak otot tungkai mengalami peningkatan dan hal tersebut sudah dijelaskan pada hasil analisis data yang sudah dilakukan. Hal ini sejalan dengan salah satu prinsip latihan yaitu prinsip peningkatan latihan dimana peningkatan kinerja atlet merupakan pengaruh langsung dari kuantitas dan kualitas kerja yang diperoleh karena latihan. Mulai dari tingkat pemula sampai ke tingkat tinggi, beban kerja latihan harus bertambah secara bertahap dan berangsur. Dalam meningkatkan kondisi fisik atlet Selalu terkait dengan tiga faktor utama, yaitu frekuensi latihan, intensitas latihan, dan waktu latihan atau durasi. (Harsono, 2018)

\section{Kesimpulan}

Berdasarkan hasil penelitian yang telah dilakukan dan diperkuat dengan hasil analisis statistik inferensial, maka dapat disimpulkan bahwa: Tidak terdapat perbedaan yang 
pengaruh tutor sebaya terhadap hasil pembelajaran lay up shoot bola basket pada siswa SMP Islam Nurul Huda ditunjukkan nilai sig.(2-tailed) dari kelompok eksperimen yaitu 0,778 . Tidak terdapat perbedaan yang signifikan pengaruh video tutorial terhadap hasil pembelajaran lay up shoot bola basket pada siswa SMP Islam Nurul Huda ditunjukkan oleh nilai sig.(2-tailed) dari kelompok eksperimen yaitu 0,170. Tidak ada perbedaan tutorial teman sebaya dan vidio tutorial berpengaruh secara bersama terhadap pembelajaran bola basket. ditunjukkan nilai signifikansi $>0,005$.

\section{Daftar Pustaka}

Adven, FC (2010). Makna Sampul Majalah Cosmogirl Indonesia (Analisis Semiotik tentang Gaya Hidup Remaja Perempuan dalam Sampul Majalah Cosmogirl Indonesia Tahun 2009).

Christiani, R. (2018). STRATEGI MARKETING PUBLIC RELATION PT. DBL INDONESIA DALAM KEGIATAN PROMOSI FILM MATA DEWA (Disertasi Doktor, STIKOM YOGYAKARTA).

Darmawati, D. KEMAMPUAN SISWA DALAM MEMPELAJARI PRONOUNCIATION MENGGUNAKAN DIALOG PENDEK DI KELAS DELAPAN SMPN 9 BANJARBARU TAHUN 2016/2017. PROSEDUR , 182.

Daniyantara, D., Suryadi, L. E., \& Nuhayadi, S. A. (2020). Perbandingan Tingkat Keterampilan Dribbling Dengan Metode Latihan Slalom Dribbling Dan Tepukan Dribbling. Jurnal Porkes, 3(1), 49-52.

Daniyantara, D. (2018). Pembangunan Olahraga Kota Selong Kabupaten Lombok Timur Ditinjau Dari Sport Development Index. Jurnal Porkes, 1(2), 32-36.

Dai, A., Hadjarati, H., \& Haryanto, A. I. (2021). Gaya resiprokal untuk meningkatkan keterampilan shooting bola basket. Altius: Jurnal Ilmu Olahraga dan Kesehatan, 10(1), 53-65.

Erwan, M. T., \& Nopiana, R. (2018). Pengaruh Variasi Pembelajaran Terhadap Hasil Belajar Tehnik Dasar Passing Chest Pass Bola Basket. Jurnal Porkes, 1(1), 14-20.

Fitriansah, A. R. (2015). UPAYA MENINGKATKAN HASIL BELAJAR TEKNIK LAY UP SHOOT BOLA BASKET DENGAN MENGGUNAKAN METODE TUTORIAL TEMAN SEBAYA (Doctoral dissertation, Universitas Negeri Semarang).

Harsono. (2018). Kepelatihan Olahraga Teori dan Metodologi (A. Kamsyah (ed.)). PT REMAJA ROSDAKARYA.

Iqbal, R., Julianti, R. R., \& Dimyati, A. (2019). Pengguna Model Pembelajaran Teman Sebaya (Peer Teaching) Dalam Teknik Dribble Pemainan Bola Basket. Jurnal Porkes, 2(2), 37-43.

Jusran, S. (2021). Analisis Komponen Fisik Terhadap Kemampuan Shooting. Jurnal Porkes, 4(1), 55-61.

Kasiram, M. (2008). Metodologi Penelitian. UIN-Malang Pers.

Mertayasa, K., Rahayu, S., \& Soenyoto, T. (2016). Metode latihan plyometrics dan kelentukan untuk meningkatkan power otot tungkai dan hasil lay up shoot bola basket. Journal of Physical Education and Sports, 5(1), 24-31.

Oki Chandra. (2019). KETERAMPILAN LAY UP SHOOT BOLA BASKET (Setyaingrum (ed.)). MEDIA SAHABAT CENDEKIA.

Pohan, AE (2020). Konsep pembelajaran berani berbasis pendekatan ilmiah . CV. Sarnu Untung.

Puriana, R. H. (2019). Uji Kelincahan Terhadap Pelatihan Ladder Drill Quick Feet dan Ladder Drill The Boxer pada Atlet Ikasi Siduarjo. Jurnal Porkes, 2(2), 64-72. 
Pelamonia, S. P., \& Hariadi, H. (2019). Pengaruh Pelatihan Tricep Dips dan Tricep Kickback Terhadap Peningkatan Otot Lengan Atlet Bola Basket. Jurnal Porkes, 2(2), 32-36.

Sadiman, A. S. dkk. (2008). (2008). Media Pendidikan: Pengertian, Pengembangan, dan Pemanfaatannya. PT Raja Grafindo Perkasa.

Sudjatmiko, S. P. (2021). Metode Tutor Sebaya (Peer Tutoring) Dalam Pembelajaran Gambar Teknik Di SMK.

Suprayogo, P. (2021). Pengembangan Video Tutorial Olahraga Anggar Bagi Masyarakat Umum (Doctoral dissertation, Universitas Jambi). 